\title{
Effect of shear span-to-depth ratio on the shear behavior of BFRP-RC deep beams
}

\author{
Siyam Alhamad ${ }^{1}$, Yasser Al Banna ${ }^{1}$, Ahmad Al Osman ${ }^{1}$, Jihad Mouthassseeb ${ }^{1}$, Suliman \\ Abdalla $^{2}$, and Farid Abed $^{3, *}$ \\ ${ }^{1}$ Bachelor in Engineering, Department of Civil and Environmental Engineering, AUS, Sharjah, UAE. \\ ${ }^{2} \mathrm{PhD}$ Candidate, Department of Building, Civil \& Environmental Engineering, Concordia University, \\ Quebec, Canada. \\ ${ }^{3}$ Professor, Department of Civil and Environmental Engineering, AUS, Sharjah, UAE.
}

\begin{abstract}
This study investigates the shear behavior of deep concrete beams reinforced with basalt fiber reinforced polymer (BFRP) bars for flexure without web reinforcements. The experimental testing performed herein consisted of a total of 4 short beams, three of which were reinforced with BFRP and one beam was reinforced with steel bars. The primary test variable was the shear-span-to-effective-depth ratio $(a / d)$ and its influence on the beams' mid-span deflections, shear capacity, load-deformation relationships and the failure modes.
\end{abstract}

\section{Introduction}

Infrastructure deterioration due to corrosion of steel reinforcement is one of the biggest challenges facing the construction industry. Fiber Reinforced Polymer (FRP) bars are good candidate to replace steel bars in construction. The number of studies on the response of RC structural elements reinforced with FRP bars is rising. Current research on BFRP bars has proven their efficiency in bond durability [1-2] and to reinforce slender beams [3-4]. However, the study of short (deep) beams reinforced with BFRP bars is lacking in literature.

Slender beams and flexural structural elements reinforced longitudinally with FRP bars suffers in practice from large deformations and wide cracks due to reinforcements low modulus of elasticity. On the contrary, load transfer in short beams differs greatly from that in slender ones. Tied arch action is the mechanism by which short beams transfer loads where the concrete extending from the loading point to the nearest support act as compression diagonal struts and the longitudinal reinforcements act as the tie. Given the high tensile strength of FRP bars compared to regular steel ones, it is believed that FRP bars would greatly enhance the tied arch mechanism in short beams.

\footnotetext{
* Corresponding author: fabed@aus.edu
} 
Omeman et al. [5] reported the results of testing twelve short beams reinforced with steel and carbon-FRP (CFRP). The study examined variables such as $a / d$, reinforcement ratio $(\rho)$, concrete compressive strength $\left(f_{c}^{\prime}\right)$ and beams effective depth $(d)$. It was found that CFRP-beams exhibited higher shear capacities in comparison to their steel counterparts. Also, CFRP-beams had larger crack width than steel-beams near failure. Abed et al. [6] experimentally investigated the response of nine GFRP-reinforced short beams. The study considered the effect of variables such as $a / d$ ratio, $\rho, f_{c}$ and $d$ on the beams shear capacity and overall response. It was noted that GFRP-beams exhibited lower stiffness and larger mid-span deflections when compared to their steel counterparts. This was attributed to the low modulus of elasticity of the GFRP bars compared to regular steel. Moreover, twelve short beams reinforced with GFRP bars were tested and analyzed by Andermatt and Lubell [7]. The study examined the influence of $a / d$ ratio, $f_{c}$ and $d$ on the short beams response and on the accuracy of Strut-and-Tie Models (STM). The STM method adopted by ACI 318-08 [8] and CSA S806-02 [9] were utilized to predict the capacity of tested beams. It was pointed out that all tested beams developed tied arch mechanism. Such an observation was derived from the uniform strains along the reinforcements and the concrete crack width and orientation. Moreover, the CSA S806-02 STM provided good predictions for the tested specimens shear capacity in comparison to ACI 318-08 STM.

In the present work, the shear response of short beams reinforced with BFRP is experimentally investigated. The effect of shear span-to-depth ratio $(a / d)$ on beams' midspan deflections, shear capacity, load-deformation relationships and the failure modes are highlighted.

\section{Experimental program}

Three BFRP-reinforced beams were tested in addition to one steel-reinforced beam that served as a reference for the BFRP-beams. The test matrix of the experimental program is shown in Table 1.

Table 1. Test matrix and specimen details

\begin{tabular}{ccccc}
\hline Beam & $a / d$ & Load $(\mathrm{kN})$ & Deflection $(\mathrm{mm})$ & Failure mode \\
\hline B1-BFRP & 1.15 & 213.0 & 16.28 & Concrete Crushing at Horizontal Strut \\
B2-BFRP & 1.48 & 159.2 & 14.65 & Splitting at the Diagonal Strut \\
B3-BFRP & 1.82 & 79.5 & 7.85 & Splitting at the Diagonal Strut \\
\hline B4-STL & 1.15 & 206.9 & 9.69 & Splitting in the Diagonal Strut \\
\hline
\end{tabular}

\subsection{Test specimen and setup}

The test specimen was $2000 \mathrm{~mm}$ long with a rectangular cross section of $140 \mathrm{~mm}$ wide. The effective depth of the beams was kept the same for all four beams at $260 \mathrm{~mm}$. Different span-to-depth ratios, $a / d=1.15,1.48$, or 1.82 , were attained by changing the distance between the loading points. A concrete cover of $45 \mathrm{~mm}$ measured from the soffit of the beam to the center of the reinforcing bars was maintained in all of the tested beams.

The beams were tested under four-point loading configuration with a clear span of $1000 \mathrm{~mm}$ and $500 \mathrm{~mm}$ overhang on each side to provide sufficient anchorage length for the 
longitudinal bars. A schematic of the test setup with cross-section dimensions and reinforcement details of the test specimen is shown in Fig. 1. All beams were instrumented at mid-span with $5 \mathrm{~mm}$ strain gauges bonded to the tensile bars. The beams were loaded at a constant rate of $0.6 \mathrm{kN} / \mathrm{s}$ in load control until failure occurred using an Instron actuator of $2000 \mathrm{kN}$ capacity. Cracks initiation and propagation were manually recorded for each specimen at each stage of loading. Beams deflections were measured by means of linear variable differential transducers (LVDTs) mounted at beams mid-span. A data acquisition captured the readings of strain gauges and LVDTs at all stages of loading.

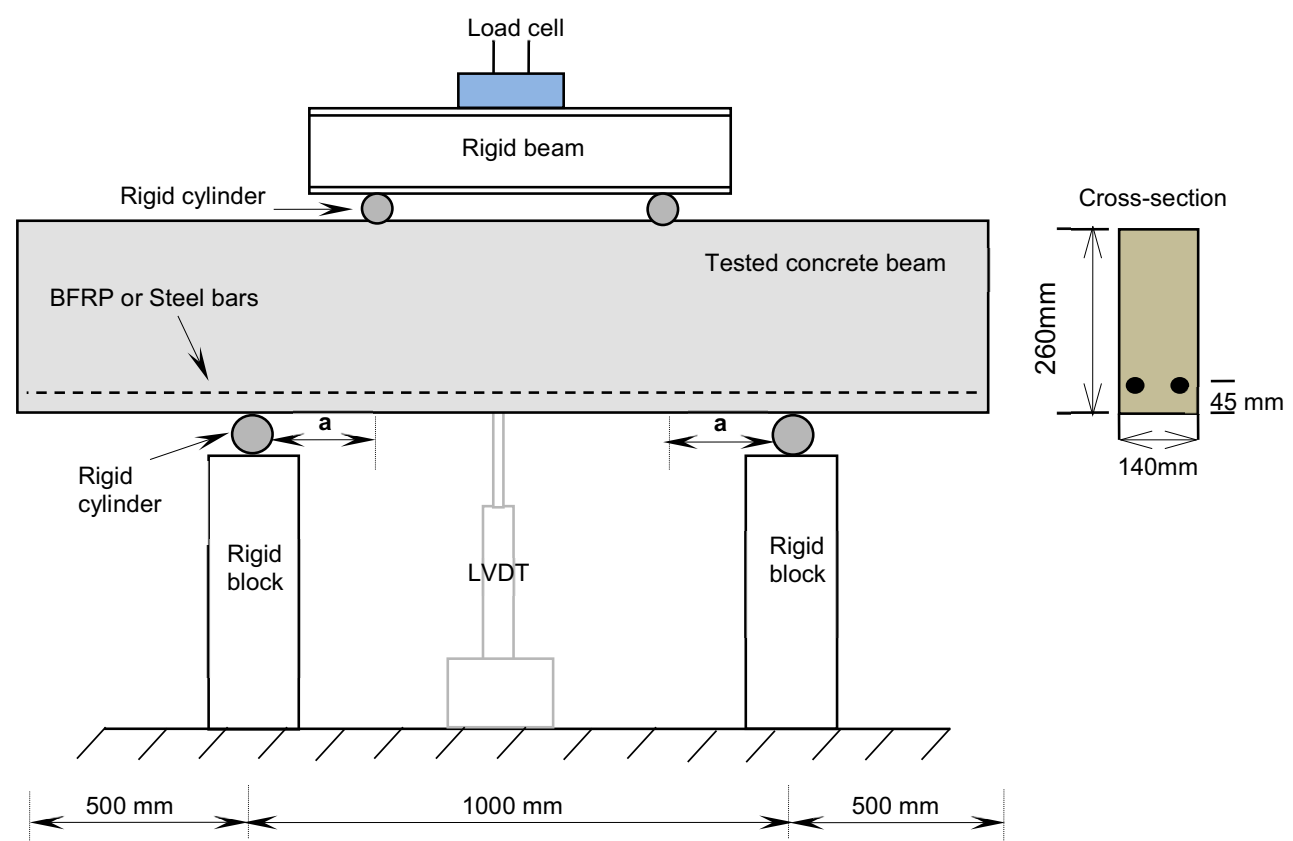

Fig. 1. Schematic of test setup with cross sections and reinforcement details

\subsection{Materials}

A ready-mix concrete with compressive strength of $40 \mathrm{MPa}$ was considered. The concrete compressive strength was measured by standard concrete cubes of $150 \mathrm{~mm}$ tests. Steel bars of nominal yield strength of $460 \mathrm{MPa}$ and elastic modulus of $200 \mathrm{GPa}$ were used to reinforce the control specimens.

The actual diameters of the BFRP bars used in this study were measured by volume displacement as recommended by the ACI 440.3R-04 committee [8]. The $12 \mathrm{~mm}$ BFRP bars have a uniform sand coating with shallow spiral indentations spaced at $2.75 \mathrm{~mm}$ along their surface. The mechanical properties of these BFRP bars were obtained by conducting tensile tests for 5 specimens. The average ultimate stress and elastic modulus were measured as $1230 \mathrm{MPa}$ and $46.2 \mathrm{GPa}$, respectively. 


\section{Results and discussion}

\subsection{Failure modes}

Fig. 2 shows sample photos of the failed beams (B1-BFRP and B2-BFRP) where all specimens collapsed in shear. A small crack propagating from one of the supports to the nearest loading point diagonally resulted in the beam failure. This typical shear failure was expected due to the absence of shear reinforcements in the beams.

Shear failure of the BFRP-reinforced beams B1-BFRP was accompanied by the top concrete crushing between the two point loads. In beam B2-BFRP, concrete in compression crushed under the point load that connected the shear failure crack to the support. It is worth noting that beams that showed top concrete crushing exhibited a more ductile failure at ultimate than other beams that failed with only diagonal shear cracks.
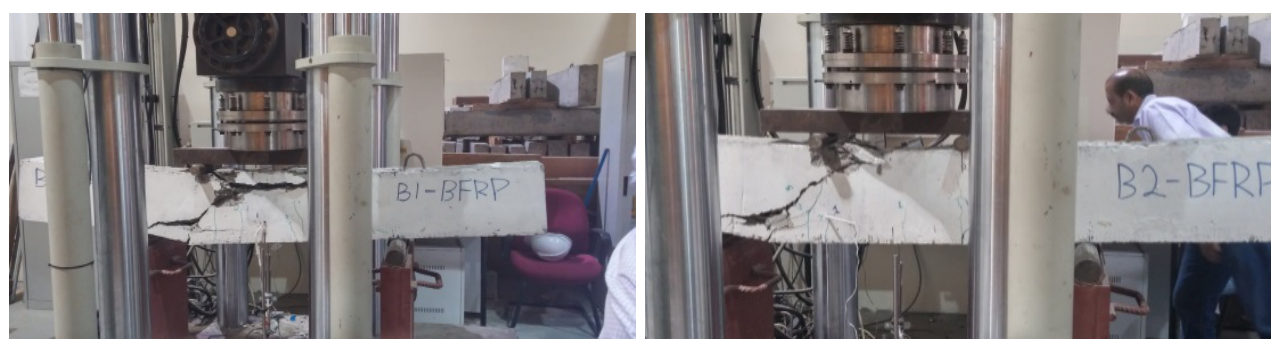

Fig. 2. Failure modes for selected beams

\subsection{Load-deflection relationships}

The load-deflection relationships of the tested BFRP-beams and the control Steel-beam are shown in Fig. 3. The BFRP-reinforced beams exhibited almost linear load-deflection curves after cracking unlike the steel beams that showed elasto-plastic load-deflection curves until failure occurred. It can be noted from Fig. 3 that increasing the $a / d$ ratio increases the midspan deflection measured at any stage of loading. This finding was explained by the tendency of beams having large $a / d$ ratios to behave as a flexure-critical member rather than a shear-critical one. Smaller deflection was exhibited by the steel-beam which is noted from the higher post-cracking stiffness compared to BFRP counterpart. The small postcracking stiffness encountered in the BFRP-reinforced beams was attributed to the low modulus of elasticity of the BFRP bars compared to that of the steel bars, which resulted in wider cracks.

All of the BFRP-beams showed an abrupt failure when their ultimate shear capacities were attained as illustrated in Fig. 3. The brittle failure of the BFRP-specimens can be noticed from the load-deflection response of beam B3-BFRP. The sudden drop at ultimate indicated the collapse of the beams once their ultimate strength was achieved without showing any residual deformations. On the contrary, B1-BFRP showed a more ductile behavior that was attributed to the concrete crushing in compression between the two point loads prior to collapse. The load-deflection response was also consistent with the strain gauge readings along the bars. It is worth pointing out that the recorded strains showed no sign of anchorage problems in any of the beams. Prior to cracking, the strains in the tensile reinforcement were insignificant. However, after cracking the strains increased significantly as a result of the formed cracks. Strains recorded in the steel-reinforced bars were less than those recorded in their BFRP-reinforced counterparts at all stages of loading 


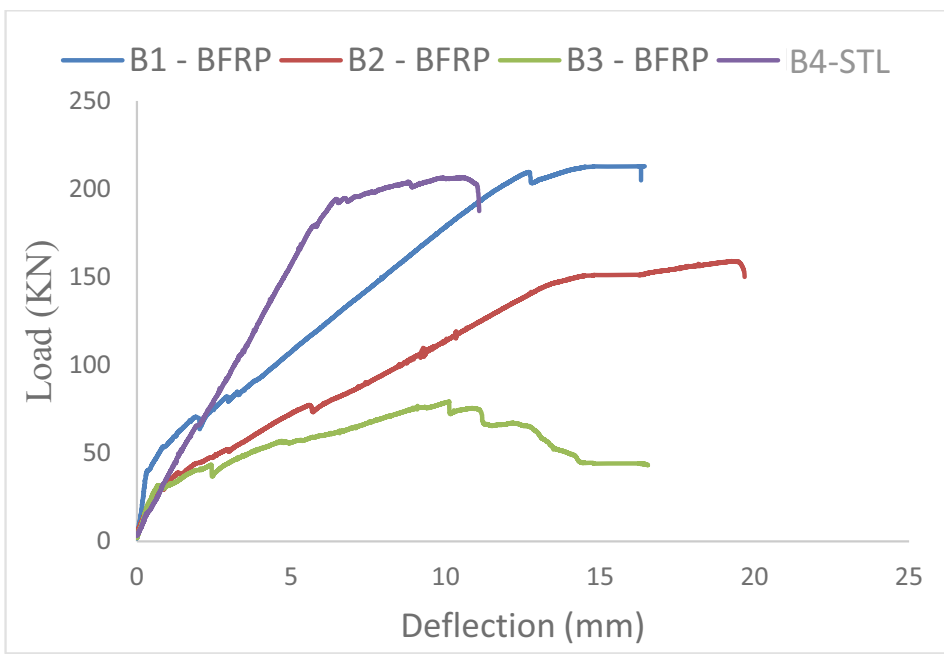

Fig. 3. Effect of $a / d$ on the Load-Deflection Relationship

\subsection{Strength analysis}

The tested beams shear capacities and maximum deflections are summarized in Table 1. The results suggest that BFRP-beams recorded slightly higher ultimate loads than the steel counterpart. It should be emphasized that the deflection at ultimate load of the BFRP-beams was higher than that of their steel counterpart as a result of the low modulus of the BFRP bars compared to steel ones.

Fig. 4 correlates the tested beams shear strength to their $a / d$ ratio. A linear inverse proportionality can be noted between shear strength to their $a / d$ ratio. Also, decreasing $a / d$ ratio by $19 \%$ from 1.82 for specimen B3-BFRP to 1.48 for specimen B2-BFRP lead to an increase in the shear capacity by $100 \%$ from 79.5 to $159 \mathrm{kN}$, respectively. Additional reduction of the $a / d$ ratio by $22 \%$ to a ratio of $a / d=1.15$ in B1-BFRP resulted in $34 \%$ capacity increase.
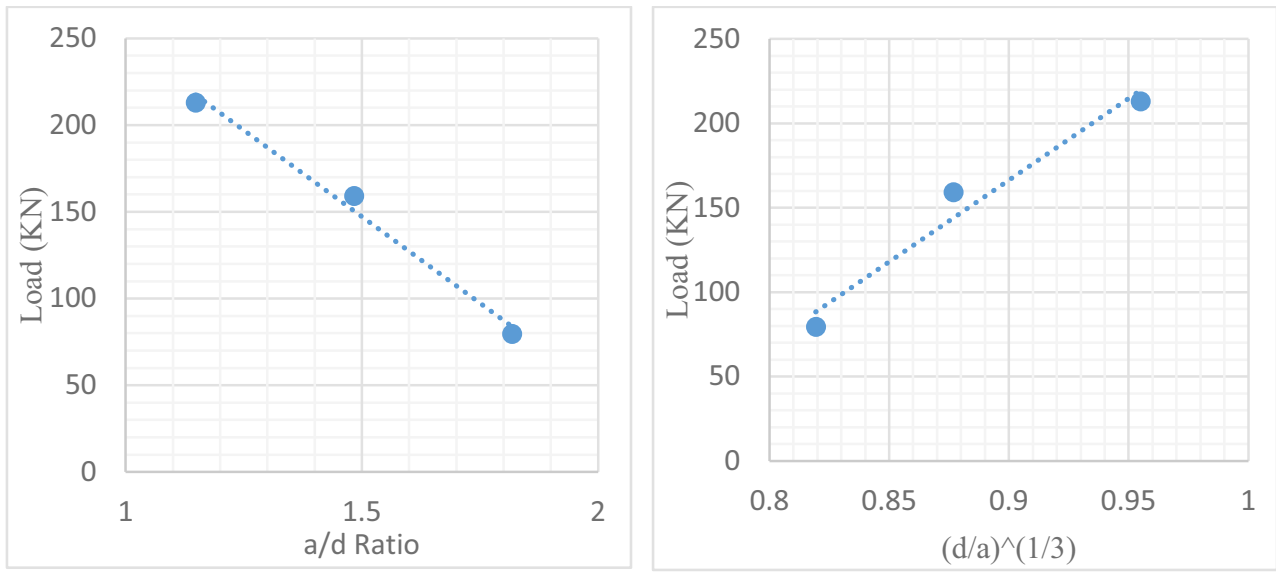

Fig. 4. Effect of $a / d$ on the shear capacity of FRP-reinforced concrete short beams 
It is also observed from Fig. 4 that the shear strength of BFRP-RC beams is proportional to the cubic root of the span to depth ratio [(d/a)1/3]. This linear proportionality is in agreement with the recommendations of the Canadian standard S806-02 (CSA, 2002) [9] as given by the following equation 1 .

$$
V_{c}=0.05 \lambda \phi_{c} k_{m} k_{r} k_{a}\left(f_{c}^{\prime}\right)^{\frac{1}{3}} b_{w} d_{v}
$$

Where

$$
\begin{aligned}
& k_{m}=\sqrt{\frac{V_{f} d}{M_{f}}} \leq 1.0 \\
& k_{r}=1+\left(\rho_{w} E_{F}\right)^{\frac{1}{3}} \\
& k_{a}=\frac{2.5}{M_{f} / V_{f} d} \geq 1.0
\end{aligned}
$$

Here $\lambda$ is the concrete density factor, $\phi_{c}$ is the concrete resistance factor, and $\rho_{w}$ is the longitudinal reinforcement ratio percentage, $d_{v}$ is the effective shear depth taken as the greater of $0.9 \mathrm{~d}$ or $0.72 \mathrm{~h}(\mathrm{~mm}), E_{F}$ is the modulus of elasticity of FRP bars (MPa), $V_{f}$ is the factored shear $(\mathrm{N}), M_{f}$ is the factored moment (N.mm), $d$ is the effective depth (mm), and the quantity $V_{f} d / M_{f}$ is the inverse of $a / d$. The correlation between $V_{c}$ and $a / d$ in equation (1) can be derived from the multiplication of factors $k_{m}=\sqrt{V_{f} d / M_{f}}=1 / \sqrt{a / d}$ and $k_{a}=$ $2.5 /\left(\mathrm{M}_{\mathrm{f}} / \mathrm{V}_{\mathrm{f}} \mathrm{d}\right)=2.5 /(\mathrm{a} / \mathrm{d})$.

\section{Conclusions}

This paper reports on the experimental testing of Basalt-FRP reinforced deep beams and a steel RC counterpart for reference. The main variable in consideration is the shear span to effective depth ratio $(a / d)$. It was found that all beams failed by a diagonal crack that extended from the support to nearest loading point. Also, higher ductility was noted near failure for beams that showed top concrete crushing in addition to typical diagonal shear crack. The overall BFRP-RC beams exhibited higher mid-span deflections and less stiffness compared to their steel counterparts. This is attributed to the low modulus of elasticity of the BFRP bars in comparison to steel bars. Increasing the $a / d$ ratio increased the mid-span deflection due to the tendency of beams with large $a / d$ ratios to behave as a flexure-critical member rather than a shear-critical one. Moreover, a linear correlation between the shear capacities and the cubic root of $a / d$ ratio was evident from experimental result which agrees with the CSA S806-12 code. This correlation is attributed to the inclination of the angle between the diagonal compression struts and the horizontal tie which resulted in improving the beam's arch-action mechanism. 


\section{References}

1. Z. Omeman, M. Nehdi, H. El-Chabib, Can. J. Civil. Eng. 35, 1 (2008)

2. F. Abed, H. El-Chabib, M. AlHamaydeh, J Reinf. Plast. Comp. 31,1063 (2012)

3. A. Al-Tamimia, F. Abed, A. Al-Rahmani, Adv. Concrete. Const. 2, 1 (2014)

4. American Concrete Institute. ACI 440.3R-04 (2004)

5. Canadian Standards Association. CSA S806 (2012)

6. A. Altalmas, A. El Refai, F. Abed, Constr. Build. Mater. 81, 162 (2015)

7. A. El Refai, F. Abed, A. Altalmas, J. Compos. Const.-ASCE 19, 04014078 (2014)

8. A. El Refai, F. Abed, J. Compos. Const.-ASCE, 20, 040150824 (2015)

9. A. El Refai, F. Abed, A Al-Rahmani, Constr. Build. Mater. 96, 518 (2015) 